\title{
THE STATE OF THE MYOCARDIUM, THE VASCULAR WALL AND THE SEVERITY OF ANXIETY-DEPRESSIVE DISORDERS IN PATIENTS WITH MYOCARDIAL INFARCTION AND ATRIAL FIBRILLATION
}

\section{N.N. Neobutov, S.V. Kolbasnikov} Tver State Medical University of the Ministry of Health of Russia, Tver,
Russia

ABSTRACT - In patients with myocardial infarction with atrial fibrillation, the relationship between vascular wall parameters, structural and functional changes in the myocardium, and the severity of emotional disorders were clarified. 138 inpatients of the cardiology department were closely monitored. It turned out that patients with myocardial infarction and a constant form of atrial fibrillation, unlike patients with paroxysmal form, show significant structural changes in the myocardium, endothelial dysfunction with a reduction in wall elasticity, which must be considered during therapeutic and preventive, rehabilitation measures.

KEY W ORDS - myocardial infarction, atrial fibrillation, vascular wall stiffness, anxiety and depressive disorders.

\section{INTRODUCTION}

Atrial fibrillation is a frequent complication of acute myocardial infarction [12], significantly aggravates the patient's condition, leads to deterioration of hemodynamic parameters and the appearance of recurrent myocardial ischemia $[3,4,7]$. Currently, a large amount of data on the causes, electrophysiological mechanisms and hemodynamic consequences of the development of atrial fibrillation in myocardial infarction has been accumulated [13]. However, a number of issues related to this arrhythmia appear to be insufficiently studied. These include the structure of anxiety-depressive disorders, the state of the elastotonic properties of the vascular wall, endothelial function and cardiac remodeling in patients with myocardial infarction with various forms of atrial fibrillation, which requires detailed study.

To evaluate parameters of the contour analysis of Objective the pulse wave and endothelium function, as well as structural and functional changes in the myocardium and the severity of emotional disorders in patients with myocardial infarction in various forms of atrial fibrillation.
Article history:

Received 13 March 2019

Received in revised form 23 March 2019

Accepted 1 April 2019

\section{MATERIALS AND METHODS}

138 patients were examined ( 63 men, 75 women) who were hospitalized in the cardiology department of the City Clinical Hospital No. 7 with a diagnosis of myocardial infarction with atrial fibrillation. Depending on the form of atrial fibrillation, the patients were divided into 2 groups: the $1^{\text {st }}$ was $83(60.1 \%)$ patients with paroxysmal form, the $2^{\text {nd }}$ group was 55 (39.9\%) with the permanent form. The survey was conducted in the first three days of hospital stay.

Conducted: general clinical examination, localization of myocardial infarction, its frequency rate (primary, repeated) $[4,7,12]$, complications (acute left ventricular failure according to Killip, 1967) [10] were studied. All patients were determined plasma lipid spectrum (total cholesterol, low density, high density lipoproteins, triglycerides; $\mathrm{mmol} / \mathrm{l}$ ) while taking lipidlowering drugs (atorvastatin 40-80 mg/day) [9]. An echocardiographic study was performed on a Vivid I apparatus (GE Healthcare UK) with an assessment of the following parameters: ejection fraction (EF\%), end diastolic size of the left ventricle (CRLLD; $\mathrm{mm}$ ), end diastolic volume of the left ventricle (CEDI; ml), posterior wall thickness of the left ventricle (TSSLZH; mm), thickness of the interventricular septum (TMZHP; mm), size of the left atrium (LP; mm), right atrium $(\mathrm{PP} ; \mathrm{mm})$, right ventricle $(\mathrm{RV} ; \mathrm{mm})$, systolic pressure in the pulmonary artery (SDLA; mm rt.art.) [6]. The rigidity of the vascular wall was studied by the photoplethysmographic method (apparatus Angioscan-1) in the morning in a quiet darkened room, strictly on an empty stomach; before the procedure, the patients did not smoke or drink tea or coffee. Immediately before the procedure, the patient was at least 10 minutes at rest. The test was carried out in a sitting position with fixed hands. The procedure for performing a contour analysis was carried out in several stages:

1. Measurement of blood pressure by the standard oscillometric method using a certified device;

2. Entering the patient's data (level of blood pres- 
sure, height, weight, date of birth) into the AngioScan computer program;

3. Installation of the optical sensor on the end phalanx of the index finger of the right hand;

4. Registration and automatic evaluation of pulse waves.

Based on the contour analysis of the photoplethysmogram [1], the following were evaluated: pulse rate (PE; beats/min), stiffness index (SI - Stiffness index; $\mathrm{m} / \mathrm{s})$, reflection index (RI - Reflection Index; $\%$ ), amplitude occlusion index (IRA; \%), increase index (Alp - Augmentation index;\%), increase index normalized for pulse rate $(\mathrm{CP}=75)$ (Alp $75-$ Augmentation index @ HR=75), age index (AGI - Aging Index), vascular age (VA — Vascular Aging; years), duration of systole (ED - Ejectuon Duration; m/s), pulse wave duration (PD - Pulse Duration; $\mathrm{m} / \mathrm{s}$ ), central systolic pressure (Spa - Systolic Pressure Aortic - prognosis, $\mathrm{mm} \mathrm{Hg}$ ), type of pulse wave (A, $\mathrm{B}, \mathrm{C}$ ). To assess the endothelial function, a test was performed with reactive hyperemia with the calculation of the occlusion index by amplitude (IOA; used units) and phase shift (MF; ms) between the channels. The occlusion of the brachial artery was carried out for 5 minutes by inflating the standard cuff of the tonometer to a pressure of $50 \mathrm{~mm} \mathrm{Hg}$, exceeding the systolic pressure with simultaneous recording of the signal. After 5 minutes, the pressure in the cuff was quickly dropped to zero and the signal was recorded for 3 minutes.

To assess the severity of anxiety/depression, a scale of anxiety and depression HADS [14] was used, which includes 14 questions: part 1 contains 7 questions of anxiety; Part $2-7$ questions of depression. Each answer corresponds to a certain number of points. By the sum of points, the result was evaluated: $0-7$ points - the absence of reliably expressed symptoms of anxiety and depression, 8-10 points subclinical anxiety/depression, 11 points and above - clinically expressed anxiety/depression. For the analysis and evaluation of the obtained data, standard methods of descriptive statistics were used: the calculation of average values and standard deviation $(\mathrm{M} \pm \sigma)$ for the normal distribution. Student's t-test was used to compare groups (for quantitative variables). The level of statistical significance was taken as $p<0.05$. For statistical processing of the results obtained, Statistica version 10 was used.

\section{RESULTS}

Among patients of the $1^{\text {st }}$ group (age $71.9 \pm 8.9$ years), anterior myocardial infarction was recorded in 33 (39.7\%), lower - in 20 (24.3\%), repeated anterior - in $15(18,0 \%)$, repeated lower - in $15(18.0 \%)$ patients. In patients of the $2^{\text {nd }}$ group (age $-73.7 \pm 9.0$ years), anterior myocardial infarction occurred in 25 (45.4\%) people, lower myocardial infarction - in 17 (30.9\%), repeated anterior - in 11 (20.0\%) people, repeated lower - in 2 (3.6\%). As can be seen from the data presented in Table 1 , in patients with paroxysmal atrial fibrillation, I and II prevail, less frequently, III and IV, the functional class of acute heart failure, whereas in patients with permanent atrial fibrillation, frequency II and III increased, while I and IV functional class.

As can be seen from the data presented in Table 2, patients with a constant form of atrial fibrillation compared with the paroxysmal form, there was a statistically significant increase in LP, PP, SDLA, there was also a tendency to an increase in indicators of LVEDD, CLLT, TLSS, LV, which indicates about significant structural changes in the myocardium in patients with permanent atrial fibrillation, which are combined with signs of severe heart failure.

According to Table 3, patients with myocardial infarction with a constant form of atrial fibrillation, compared with the paroxysmal form, have a significant increase in PD, decrease in RI, as well as a tendency to increase in AGI, SI, decrease in ED, which indicates the effectiveness of elastic vascular walls in large resistive arteries. The high tone of the thin muscular arteries, in patients with paroxysmal atrial fibrillation, is an additional risk factor for heart muscle damage. In the studied groups, an increase in the frequency of the pulse waves of type A and B was noted, the type of curve $\mathrm{C}$ tended to decrease, which characterizes the decrease in the elasticity of the vascular wall. However, in individuals with a permanent form, these types of waves were encountered more frequently than in individuals with a paroxysmal form, which indicates a significant increase in the afterload of the left ventricular myocardium and a violation of its diastolic relaxation.

When assessing endothelial function in patients of the $2^{\text {nd }}$ group, compared with patients of the $1^{\text {st }}$ group, there was a statistically significant decrease in the SF, as well as a tendency to decrease in IRA, which indicates significant endothelial dysfunction in the large muscle arteries. In patients of the 1st group, there was a direct correlation of the average force between the parameters of CEDI and RI $(r=+0.536)$, AIp and Spa $(r=+0.523)$, VA and Spa $(r=+0.588)$, the inverse correlation link of a weak force between EF and RI $(\mathrm{r}=-0.492)$ and the average force between TMZHP and $\mathrm{RI}(\mathrm{r}=-0.624)$; in patients of the $2^{\text {nd }}$ group, the direct correlation of the average force between the IOA and TLSVFL $(\mathrm{r}=+0,517)$, SI and TLSAFL $(\mathrm{r}=+0,520)$, SI and TMD $(r=+0,530)$, Spa and FV $(r=+0.543)$, SI 
Table 1. The frequency of the functional class of heart failure by Killip in patients with myocardial infarction

\begin{tabular}{l|l|l|l|l}
\hline \multirow{2}{*}{$\begin{array}{l}\text { Monitoring } \\
\text { group }\end{array}$} & \multicolumn{4}{|l}{ Killip Functional Heart Failure Class } \\
\cline { 2 - 5 } & I & II & III & IV \\
\hline $1^{\text {st }} n=83$ & $57(68,6 \%)$ & $11(13,2 \%)$ & $8(9,6 \%)$ & $7(8,4 \%)$ \\
\hline $2^{\text {nd }} n=55$ & $31(56,3 \%)$ & $11(20,0 \%)$ & $9(16,3 \%)$ & $4(7,2 \%)$ \\
\hline
\end{tabular}

Table 2. Indicators of echocardiography in patients with myocardial infarction with atrial fibrillation

\begin{tabular}{l|l|l|l}
\hline \multirow{2}{*}{ Indicator } & \multicolumn{3}{|l}{ Atrial fibrillation } \\
\cline { 2 - 4 } & $\begin{array}{l}\text { Paroxysmal } \\
(\mathrm{n}=83)\end{array}$ & $\begin{array}{l}\text { Permanent } \\
(\mathrm{n}=55)\end{array}$ & $\mathrm{p}<$ \\
\hline $\mathrm{EF}, \%$ & $42,1 \pm 10,9$ & $41,6 \pm 10,6$ & - \\
\hline CRLLD, $\mathrm{mm}$ & $47,8 \pm 4,9$ & $49,1 \pm 7,6$ & - \\
\hline CEDI, $\mathrm{ml}$ & $97,7 \pm 34,0$ & $107,9 \pm 43,2$ & - \\
\hline TSSLZH, $\mathrm{mm}$ & $12,8 \pm 2,9$ & $14,3 \pm 2,4$ & - \\
\hline TMZHP, $\mathrm{mm}$ & $14,1 \pm 2,8$ & $14,3 \pm 2,4$ & - \\
\hline LP, $\mathrm{mm}$ & $4,2 \pm 0,5$ & $4,6 \pm 0,6$ & 0,001 \\
\hline PP, $\mathrm{mm}$ & $3,9 \pm 0,5$ & $4,2 \pm 0,5$ & 0,001 \\
\hline $\mathrm{RV}, \mathrm{mm}$ & $2,8 \pm 0,4$ & $3,09 \pm 0,4$ & - \\
\hline SDLA, $\mathrm{mm}$ Hg. & $38,9 \pm 13,1$ & $41,1 \pm 8,6$ & 0,05 \\
\hline
\end{tabular}

Statistical significance is indicated between patients with paroxysmal and persistent $A F(p<0.05-0.001)$

Table 3. Indicators of contour analysis of pulse wave and endothelium function in patients with myocardial infarction with atrial fibrillation

\begin{tabular}{l|l|l|l}
\hline \multirow{2}{*}{ Indicator } & \multicolumn{2}{l}{ Atrial fibrillation } \\
\cline { 2 - 4 } & $\begin{array}{l}\text { Paroxysmal } \\
(\mathrm{n}=83)\end{array}$ & $\begin{array}{l}\text { Permanent } \\
(\mathrm{n}=55)\end{array}$ & $\mathrm{p}<$ \\
\hline PD, beats/min & $541 \pm 9,4$ & $600,9 \pm 16,2$ & 0,05 \\
\hline AGI & $0,8 \pm 0,2$ & $1,1 \pm 0,4$ & - \\
\hline RI, \% & $32,2 \pm 1,7$ & $21,2 \pm 2,3$ & 0,05 \\
\hline Spa, mm Hg. & $112,6 \pm 4,1$ & $112,5 \pm 4,8$ & - \\
\hline Alp, \% & $8,8 \pm 1,3$ & $8,5 \pm 1,9$ & - \\
\hline SI, m/s & $7,8 \pm 2,0$ & $8,7 \pm 1,8$ & - \\
\hline ED, \% & $45,2 \pm 1,0$ & $40,4 \pm 7,9$ & - \\
\hline I0A; used.units. & $1,4 \pm 0,7$ & $1,15 \pm 0,6$ & - \\
\hline MF; ms & $-3,7 \pm 0,9$ & $-12,2 \pm 2,6$ & 0,05 \\
\hline Curve type A, \% & $72,1 \pm 4,2$ & $78,4 \pm 5,0$ & - \\
\hline Curve type B, \% & $19,2 \pm 3,6$ & $15,1 \pm 3,4$ & - \\
\hline Curve type C, \% & $8,6 \pm 3,3$ & $6,4 \pm 2,8$ & - \\
\hline
\end{tabular}

Statistical significance is indicated between the patient and the paroxysmal and permanent form of $A F(p<0.05)$. and RI $(\mathrm{r}=+0.569)$, AIp 75 and SI ( $\mathrm{r}=+0.706)$, AIp 75 and $\mathrm{RI}(\mathrm{r}=+0.712)$.

When studying anxiety disorders in patients with myocardial infarction with atrial fibrillation, it was found that in patients with paroxysmal and persistent atrial fibrillation, no statically significant changes were detected. As can be seen in Fig. 1, patients with myocardial infarction with a paroxysmal form of atrial fibrillation in most cases lacked anxiety, then subclinical and less often clinically expressed anxiety was recorded. In patients with myocardial infarction with a constant form of atrial fibrillation, in contrast to those with paroxysmal form, the frequency of subclinical and clinically severe anxiety increased. In the 1st group, among individuals with no anxiety, the level on the HADS scale was $3.59 \pm 2.0$ points, with subclinical anxiety $-8.9 \pm 0.8$ points, with clinically severe anxiety $-12.0 \pm 0.1$ points; in patients of the $2^{\text {nd }}$ group, respectively, $3.6 \pm 1.8 ; 8.8 \pm 0.7 ; 12.0 \pm 0.9$ points.

When studying depressive disorders (Fig. 2), among patients in the $1^{\text {st }}$ group, the frequency of subclinical and clinically severe depression was higher than in the $2^{\text {nd }}$ group. In the first group among individuals with no depression on the HADS scale, its level was $4.2 \pm 1.8$ points, with subclinical depression $-8.8 \pm 0.7$ points, with clinically severe depression $-12.5 \pm 0.5$ points ; in group 2 , respectively, $3.7 \pm 2.0$; $8.5 \pm 0.7 ; 13.0 \pm 0.1$ points.

\section{CONCLUSION}

In patients with myocardial infarction with a permanent form of atrial fibrillation, in contrast to patients with paroxysmal form, there are significant structural changes in the myocardium, endothelial dysfunction with a decrease in the elasticity of the arterial vascular wall. In the case of paroxysmal atrial fibrillation, emotional stress is characterized by the predominance of depressive disorders, and in permanent form, alarming, which must be taken into account when carrying out treatment-andprophylactic, rehabilitation measures and solving expert issues.

\section{REFERENCES}

1. AngioScan-01 Diagnostic complex for analyzing the state of the cardiovascular system: User Guide.- Angio Scan Electronics Ltd., 2012. - 119 p.

2. Aronov D.M. Atherosclerosis and coronary heart disease. Moscow, from the "Triad X". 2009; 245 seconds

3. BenNet, D. H. Cardiac arrhythmias [Text]: pract. rec. / D.H. Bennett; by ed. V. A. Sulimov, trans. from English M.V. Syrtsova. - Moscow: GEOTAR-Media, 2010. - $440 \mathrm{p}$. 


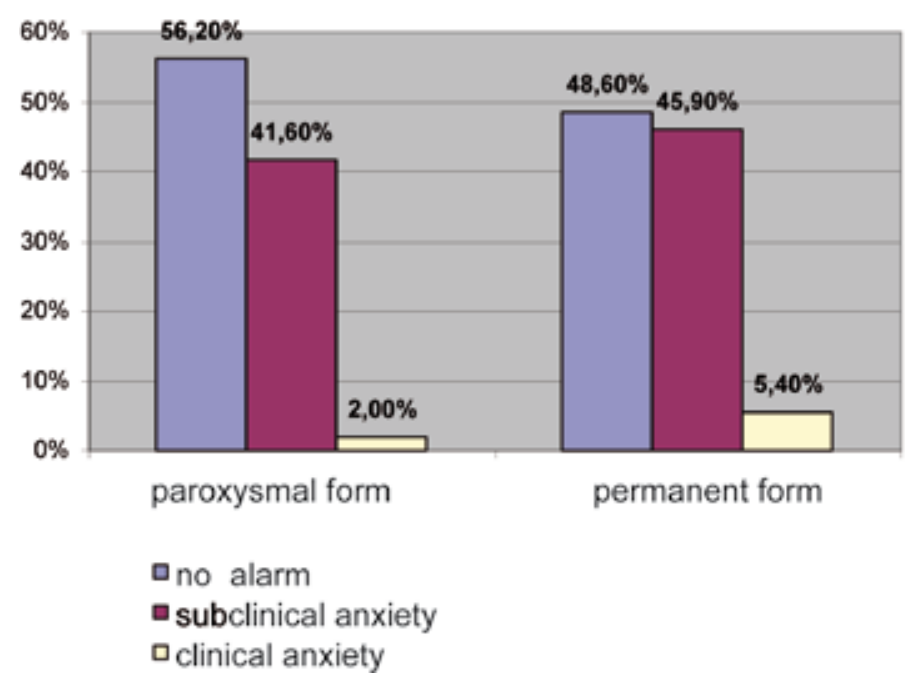

Fig. 1. Structure of anxiety disorders in patients with myocardial infarction with atrial fibrillation

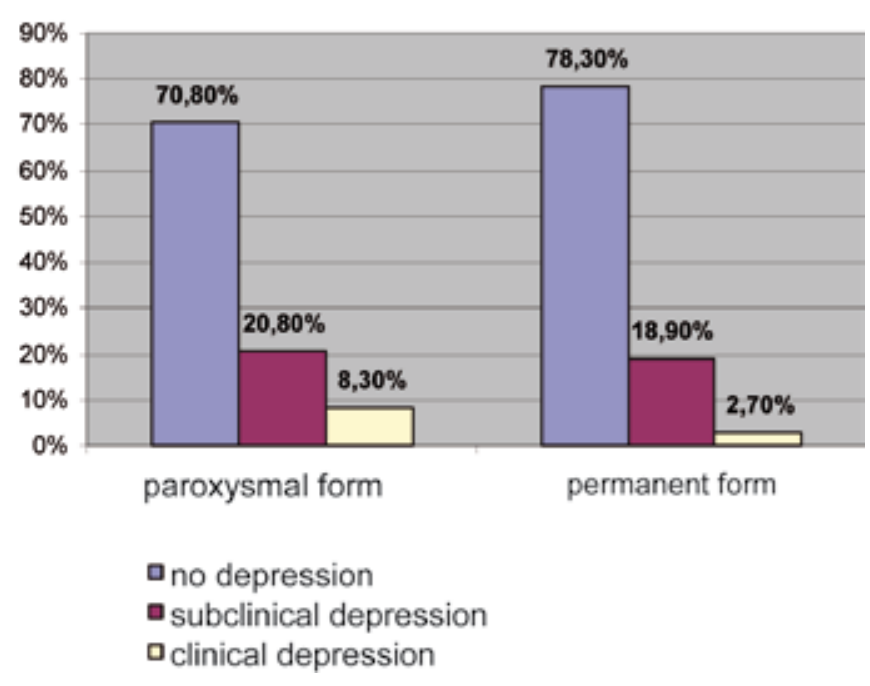

Fig. 2. The structure of depressive disorders in patients with myocardial infarction with atrial fibrillation
4. Janashia, P.H. Emergency Cardiology [Text]: Guide / P.H. Janashia, N. M. Shevchenko, S.V. Olishevko. Moscow: Binom, 2008. - 296 p.

5. Kuznetsov, S. I. Arterial hypertension and arterial hypotension: innovations in combination therapy [Text]: scientific method. manual / S. I. Kuznetsov, P. I. Romanchuk, G. G. Shishin; The Ministry of Healthcare and Social Development of the Siberian State Medical University, the Geriatric Scientific and Practical Center. - Samara: Volga-Business, 2011. 288 p. - Bibliogr .: p. 281-285

6. Ryвакоva, M.K. A practical guide to ultrasound diagnostics. Echocardiography. / Rybakova M.K., Alekhin M.N., Mitkov V.V. // Izd.dom Vidar. - Moscow. -2008 . -554 p.

7. Shakhnovich, R. M. Acute coronary syndrome with ST segment elevation [Text] / R. M. Shakhnovich. - Moscow: GEOTAR-Media, 2010. - 372 p.

8. Scales, tests and questionnaires in medical rehabilitation / ed. A. N. Belova, O. N. Shchepetova. - Moscow: Antidor, 2002. - 440 p.

9. ESC/EAS pocket guidelines. Dyslipidaemias. 2011; p. 48

10. Killip T, Kimball JT. Treament of myocardial infarction in a coronary care unit. A two-year experience with 250 patients. Am J Cardiol 1967; 20:457-464

11. Sanders JB, Aasland OG, Babor TF, de la Fuente JR, Grant M. Development of the Alscol Use Disorders Indentification Test (AUDIT): WHO Collabarative Project on Early Detection of Person with Harmful Alcohol Consumption-II. Addiction 1993; 88(6):791-804

12. Schmitt, J., Duray, G., Gersh, B.et al. Atrial fibrillation in acute myocardial infarction: A systematic review of the incidence, clinical features and prognostic implications. Eur Heart J 2009; 30:1038-45.

13. Tilling, L., Clapp B. Atrial fibrillation in myocardial infarction: predictors and prognosis Int. J. Clin. Pract. 2009;63:712-721

14. Zigmond, A.S. The hospital anxiety and depression scale / A.S. Zigmond, R.P. Snaith / Acta psychiatria Scandinavica. - 1983. - Vol.67, N6. - P. 361-370 